\section{Military Technical College Kobry El-Kobbah, Cairo, Egypt}

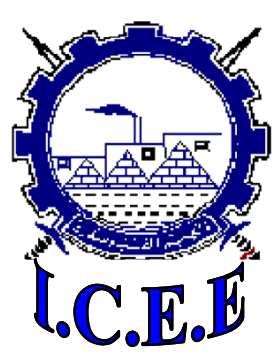

REM-3 $5^{\text {th }}$ International Conference

on

Chemical \& Environmental

Engineering

25 - 27 May, 2010.

Recent Advances in Energetic Materials

\title{
NANOTECHNOLOGY IN ENERGETIC MATERIALS
}

\author{
Mohammad.A. E. Sadek ${ }^{*}$
}

\begin{abstract}
Energetic materials are a major component of weapon system used by all branches of army. Their primary use is in explosive, as well in gun and missile propulsion. In recent years researchers have found that ene rgetic materials/ingredients that are produced on the nanoscale have the promise of increased performance in a variety of ways including sensitivity, stability, energy release and mechanical properties. As such, they represent a completely new frontier for energetic material research and development with the potential for major payoffs in weapoHns system. Very simply, nanoenergetic of energy than conventional energetic materials and one can use them in unprecedented ways to tailor the release of this energy so as to maximize the lethality of the weapons. The field of nanoenergetic R\&D is quite young, but is already undergoing rapid growth. The goal of this presentation is to give a discussion of a view selected of current research in this field.
\end{abstract}

\footnotetext{
* Higher Technological Institute, $10^{\text {th }}$ of Ramadan
} 